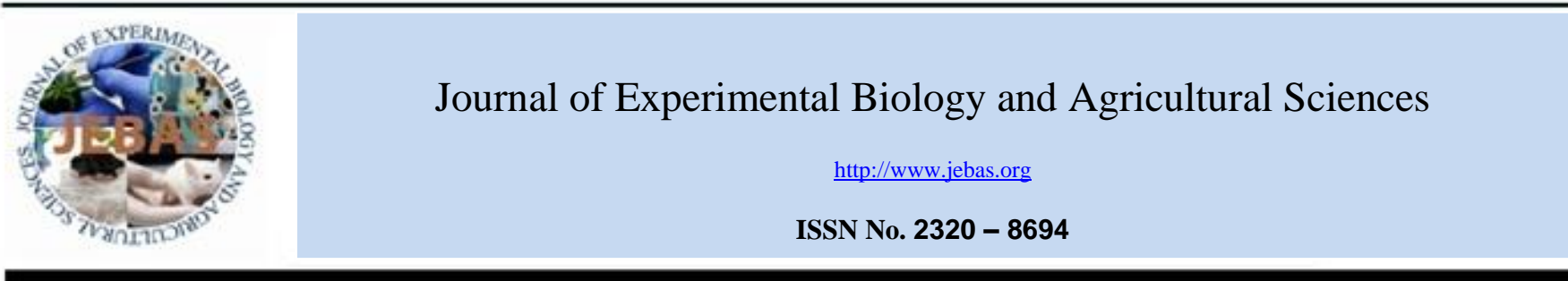

\title{
RESPONSES TO COVID-19 PANDEMIC IN A DEVELOPING COUNTRY: A SCENARIO OF BANGLADESH
}

\author{
Popy Devnath*, Imam Hossain, Mohammad Sharif Uddin, Md Hasibul Hossain, \\ Md Riyadh Al Rakib
}

Department of Microbiology, Noakhali Science and Technology University, Noakhali-3814, Bangladesh

Received - March 19, 2021; Revision - May 13, 2021; Accepted - June 10, 2021

Available Online - June 25, 2021

DOI: http://dx.doi.org/10.18006/2021.9(3).254.262

KEYWORDS
Pandemic situation
Measures
Challenges
Bangladesh
COVID-19

\begin{abstract}
Emerging at the end of 2019 in China, novel coronavirus (SARS-CoV-2) infected millions and killed thousands of people across the globe. Like other South Asian countries such as India and Pakistan, Bangladesh is also struggling to control the COVID-19 pandemic. Since the first detection on March 2020, terrible touch of the corona had been inundated Bangladesh with a total of 5,661,926 suspected patients and reported 776,257 (13.7\%) cases, 12,005 deaths (1.5\% CFR), and an overall recovery of $715,321(92 \%)$ cases as of May 11, 2020. In attempts to reduce the burden of corona cases in one of the most densely populated country of the world, the government has taken several initiatives. Bangladesh has been stepped up a large number of medical \& testing facilities, manpower, social awareness campaigns, and has taken many initial steps to fight against COVID-19. This review article is focused on the overall outbreak situation, the preparedness of the government of Bangladesh as well as challenges and limitations faced by the country so far to tackle the novel coronavirus pandemic 2019 .
\end{abstract}

* Corresponding author

E-mail: popydn.mbg@nstu.edu.bd (Popy Devnath)

Peer review under responsibility of Journal of Experimental Biology and Agricultural Sciences.

Production and Hosting by Horizon Publisher India [HPI] (http://www.horizonpublisherindia.in/).

All rights reserved.
All the articles published by Journal of Experimental Biology and Agricultural Sciences are licensed under a Creative Commons Attribution-NonCommercial 4.0 International License Based on a work at www.jebas.org.

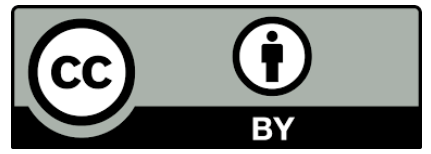




\section{Introduction}

The outbreak of the COVID-19 pandemic has been overpowered the existing advanced health systems and national preparedness strategies of many developed countries across the world (Griffin, 2020; Farsalinos et al., 2021). On the other hand, despite the growing number of cases, national emergency response plans, both health care guidelines, and public efforts have been able to reduce and confining the COVID-19 outbreak within a short period in China, South Korea, Taiwan, Vietnam, New Zealand and in many countries (Shammi et al., 2020). Briefly, it is now clear that an integrated public healthcare system and unique legislative structures focusing mainly on the current pandemic, and other actions such as mass awareness campaigns, the collaboration between government and non-government organizations, are crucial to controlling the pandemic. Yet the logistical challenges, mainly the healthcare supplies (such as personal protective equipment, ICU beds, medicines, oxygen cylinders, etc.), rapid construction of new hospitals dedicated for COVID-19 patients, and also the appointment of doctors, training of health care workers are crucially related to organizing battle against the pandemic (Gbadamosi et al., 2020; Mahajan et al., 2020).

According to a report, most of South Asian countries have inadequate pandemic preparedness compared to others (Sarkar et al., 2020). Many countries are facing a more devastating second wave than previous. The current pandemic situation of India is frightening and worsening gradually as the country reporting record-breaking infection and deaths each passing day. There is no sign of the expected epidemic growth curve being flattened. Thus, in-depth epidemiological structures, intensified case findings and contact tracing, emergency financing facilities, and other mechanisms are needed for the government of developing countries, particularly of South Asia to manage the current pandemic.

In this regard, Bangladesh could be an interesting setting to understand the characteristic of the COVID-19 pandemic from the South Asian perspective. The first case of COVID-19 patient was detected in Bangladesh on March 8, 2020, and the first causality was reported 10 days later. The increased numbers of COVID-19 positive persons and death rates have created massive pressure on the health systems of Bangladesh. With a population of over 160 million, Bangladesh is one of the most densely populated (1265 per square $\mathrm{km}$ ) countries in the world (Siam et al., 2020) and noteworthy improvement is necessary for health sectors and other administrative structures. Because of economic prosperity, the country has been experiencing an increasing trend of urbanization. However, on the other hand, the country has only 53 doctors, 0.3 nurses, 0.87 hospital beds per 1000 people, and 0.72 ICU beds and 1.1 ventilators per 100,000 people according to a published report (Islam et al., 2020a). In accordance, with other countries (Sarkar et al., 2020) the government of Bangladesh (GoB) also published the National Preparedness and Response Plan (NPRP) for managing the COVID-19 pandemic (NPRP, 2020). This response plan aimed to reduce the health threat in terms of mortality and morbidity. The country implemented several public health measures as well as multidisciplinary actions and advisory committees to execute all these approaches. And the infection rate was gradually decreased at the end of 2020. However, encountering the first wave of COVID-19 from March 2020 to February 2021 with a low death rate and low infection compared to other countries, suddenly the country is on the verge of another attack in March 2021. All over the world has been seeing an uprising of the numbers as several new variants have been reported and their mass transmission rate has been found much higher than the old one (Gómez et al., 2021; Plante et al., 2021). As mass vaccination is not feasible currently, Bangladesh again imposed different steps, including banning flights and public transports, banning mass gatherings, promoting hygiene practices and social distancing measures, etc. to combat the growing pandemic.

In this review, we focused on the overall outbreak situation, the preparedness of the GoB has faced various challenges and limitations to tackle the novel coronavirus pandemic 2019.

\section{The beginning of the pandemic in Bangladesh}

The COVID-19 epidemic was confirmed to have spread to Bangladesh in March 2020, three months later after the detection of patient zero at Wuhan, China. The first three confirmed cases were reported by IEDCR on March 8, 2020 (Shammi et al., 2020). Among them, two persons were returned from Italy and another was their family member. The patients were aged between 20 and 35 . Ten days later, the country faces the first casualty due to the virus on March 18, 2020, the patient was over 70 years old, had multiple pre-existing complications like chronic obstructive pulmonary disease (COPD), high blood pressure, heart problems, etc. The infection began a steep rise in April 2020 though it remained down till the end of March. Capital city Dhaka reported the highest cases and community transmission and adjoining city Narayanganj was reported as the epicenter of the pandemic as people spread all over the country from the districts (Moin et al., 2020).

\section{Current Pandemic Situation of Bangladesh}

As of May 11, 2021, Bangladesh has tested a total of 5,661,926 suspected patients specimens and reported 776,257(13.7\%) cases 12,005 deaths $(1.5 \% \mathrm{CFR})$, and an overall recovery of 715,321 cases (DGHS-COVID-19-Dashboard, 2020). A comparison of the top four countries with the highest death tolls revealed that the CFR of Bangladesh is similar to others except for Brazil and Mexico (Figure 1). According to WHO situation report 63, Bangladesh is 


\section{Differences of case fatality rate (CFR) of Bangladesh with highest death}

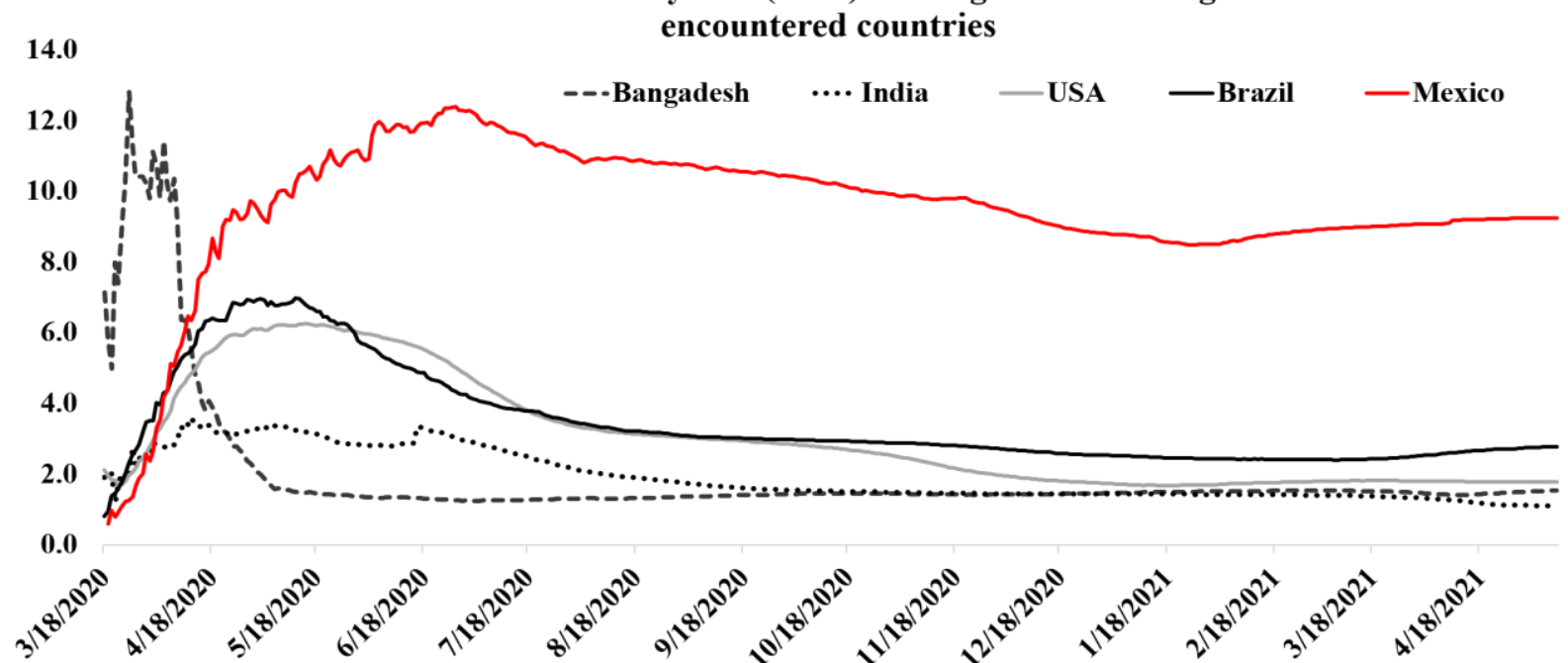

Figure 1 Differences of overall case fatality rate with countries which encountered highest deaths. Data source:

(https://ourworldindata.org/grapher/positive-rate-daily-smoothed)

\section{Monthly summarized data on COVID-19 confirmed cases}

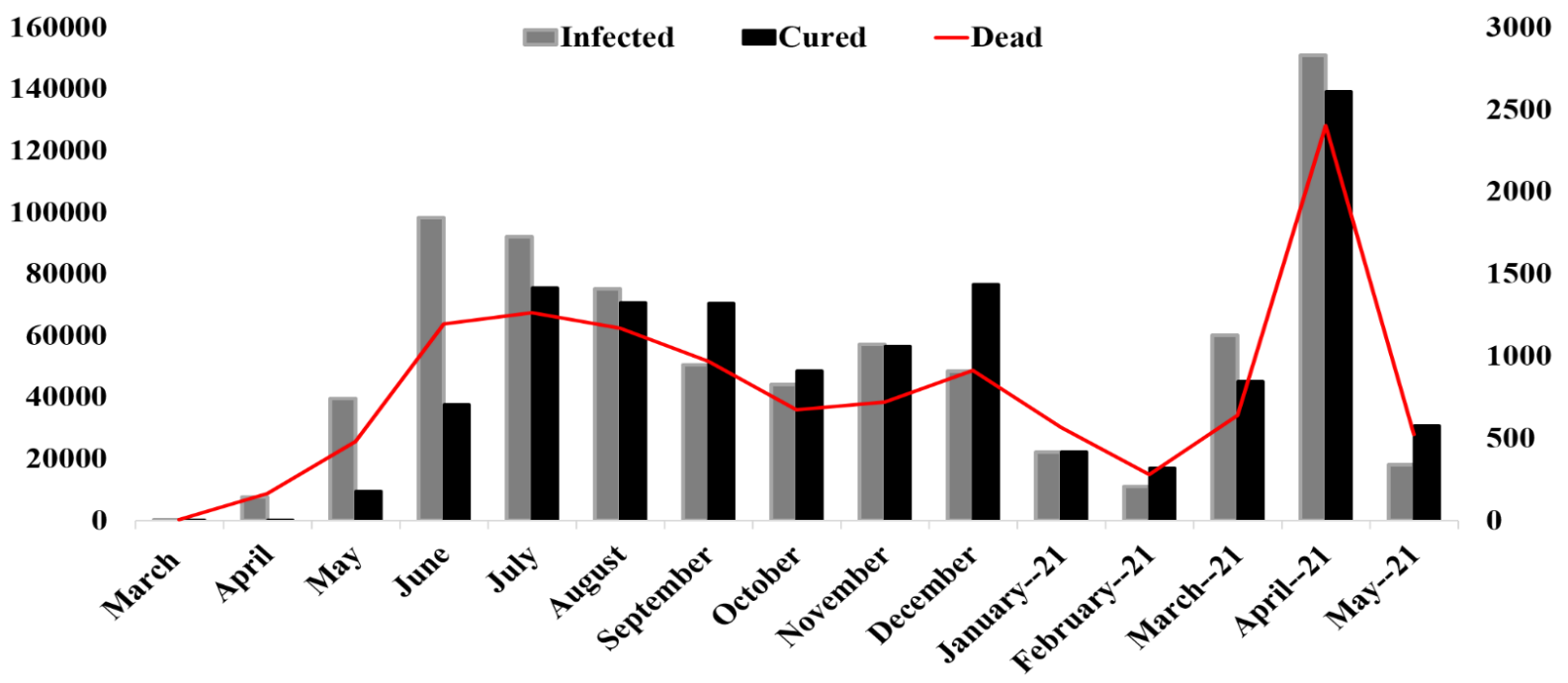

Figure 2 Overall infected, cured, and dead due to the pandemic situation in Bangladesh (data from March 2020 to May 2021. Data source: (United News of Bangladesh (2020) available at http://unb.com.bd/category/Bangladesh/virtual-trial-proceedings-begin-indhaka-courts/51449) and (HDX (2019) Novel Coronavirus (COVID-19) Cases Data Available at https://data.humdata.org/dataset/novel-coronavirus-2019-ncov-cases)

among the top 33 countries and accounts for $0.49 \%$ of the COVID19 cases of the world (WHO-Situation-Reports, 2021) and estimated to have 4558 cases and 70 deaths per million of the population (Corona.info.bd/press-release, 2020). Bangladesh had seen the highest peak in July 2020 and recently the second peak was observed in April 2021 (Figure 2). In Bangladesh, overall 62\% of confirmed cases are male and interestingly, the percentage $(72 \%)$ of death was also highest in men which are $73 \%$ as of May 
2021 (WHO-Situation-Reports, 2021). Comparatively, men are infected more than women, as the overall infection rate is 2.5 times higher in men (Siam et al., 2020). Other studies from all over the world also found that mortality from COVID-19 infection is higher in men such as in China, Europe, USA (Bwire, 2020; Jin et al., 2020; Vahidy et al., 2021). The number of deaths and confirmed cases have been steadily rising and all districts have been immersed in confirmed COVID-19 cases.

Bangladesh has altogether eight divisions. The available geographical distribution of confirmed cases describes that $70 \%$ of all confirmed cases have been reported from the Dhaka division following Chattogram (12\%), and Rajshahi (4.1\%), however, the case fatality rate was highest in Mymensingh (2.50\%) followed by Barisal (2.43\%) an Rangpur (2.38\%) (WHO-Situation-Reports, 2021).

\section{Government preparations to tackle COVID-19 pandemic in Bangladesh}

4.1 Measures adopted to restrict public movement to minimize the transmission

At the beginning of the pandemic, the government closed all communications facilities and declared public holidays for all public and private officials (Monjur \& Hassan, 2020; Shammi et al., 2020). Travelers from any corona-affected areas were advised to remain under home or institutional quarantine for two weeks after the arrival. The government also imposed lockdown across the country and deployed police and armed forces to help the administration, by forcing people to stay home, ensuring socia distancing, wearing masks, and also helping them to buy their essentials, which has been still in practice as the second wave is also affecting the country (Islam et al., 2020b). Despite withdrawing lockdown due to the low number of cases all over the country, areas with the highest confirmed cases were locked down and people coming from high-risk zone to low-infected areas were kept under quarantine facilities. Earlier authorities halt public gatherings by announcing a very big decision that limited people for prayers in the mosque, the decision was made as several reports suggested that religious gatherings were one of the major factors in the mass transmission of the virus (Quadri, 2020; Sakib, 2020) and also started virtual court to operate trial proceedings through video conference (http://unb.com.bd/category/Bangladesh/virtual-trialproceedings-begin-in-dhaka-courts/51449). Due to the pandemic, all educational institutions in the country from pre-primary to higher education were closed since March 17, 2020 (Emon et al., 2020). Classes and examinations have been taken by educational institutions through online platforms to minimize the hamper.

\subsection{Measures Adopted in Health System to Prevent the Spread} of COVID-19

To tackle the COVID-19, the Ministry of Health and Family Welfare (MoHFW, 2020), DGHS (Directorate General of Health
Services), and Institute of Epidemiology, Disease Control and Research (IEDCR) with several public health institutes have been working together for proper interventions by taking experts' opinions.

\subsubsection{Division wise dedicated health care facilities}

After the raise in COVID-19 patient cases, the government increases the number of beds in the government hospitals and converted convention centers, city corporation markets, and vacant buildings for the isolated treatment center of COVID-19 patients (Dhaka_Tribune, 2020). Around 500 government and nongovernment (without fee) hospitals prepared for COVID-19 patient's treatment and isolation center (DGHS-COVID-19Dashboard). According to a corona press release from the government, there are 6013 general and 914 ICU beds dedicated for COVID-19 treatment across the country, while around 74,000 patients are lies in the non-recovered section (Corona.info.bd/press-release, 2020). Initially, for every confirmed cases admitted, authorities provided food and accommodation free of charge during hospitalization and also in the quarantine period. In addition, knowing the unavailability of treatment options, many hospitals are currently using plasma therapy for the COVID-19 treatment (Samad et al., 2020). Telemedicine services were started to instruct COVID-19 and non-COVID-19 patients, advice includes a selection of suspicious COVID-19 cases, patients seeking help for any kind of physical problems. The directorate of general health service has given the specialized number and people in different areas can call and receive free health suggestions.

\subsubsection{Testing facilities in Bangladesh}

During international health emergencies, molecular-based approaches (the real-time RT-PCR assay) have shown to be a sensitive and specific method to detect respiratory pathogens in patients with an acute respiratory infection (Wang et al., 2020). Like other countries, Bangladesh's government also adopted the RT-PCR method for the detection of novel coronavirus. The National Reference Laboratory in Bangladesh for the COVID-19 test is at the Institute of Epidemiology, Disease Control and Research (IEDCR) in Dhaka. At the very beginning of the COVID-19 outbreak, there was very limited support available for testing services. So, the GoB instructed all the government-owned hospitals to have a "flu- corner" at outside Dhaka, so that they can collect samples from suspected COVID-19 patients and send those samples to laboratories. Moreover, gradually more laboratories are involving in testing with suspected cases rising. Up to 11 May 2021, 128 RT-PCR and 35 GeneXpert laboratories both government and non-government have been equipped with proper facilities for the test in different divisions across the country (Corona.info.bd/press-release, 2020). Along these, the DGHS has also been included in 291 COVID-19 rapid antigen testing 
facilities in government organizations to increase the testing coverage. Overall, 34,000 tests per million of the population have been reported (Our World in data, 2021 Available at https://ourworldindata.org/grapher/positive-rate-daily-smoothed).

The charge for testing SARS-CoV-2 was free for all suspected cases at the beginning later on only 200Taka (\$2.36) has been charged. The detection rate is around 10\% in May, 2020 which was around 20\% in April, 2020 (Figure 3). total of 5819900 people have taken the first dose and 3496186 completed their second dose (Corona.info.bd/press-release, 2020). Overall vaccinated people around the country are around $2 \%$. Recently India has faced a steep rise in COVID cases and due to a shortage of vaccines; the Indian government has stopped vaccine export to meet internal demand. As a result, the Bangladesh government has decided to stop administrating the first dose of vaccine temporarily from April 26, 2021, and the second dose also

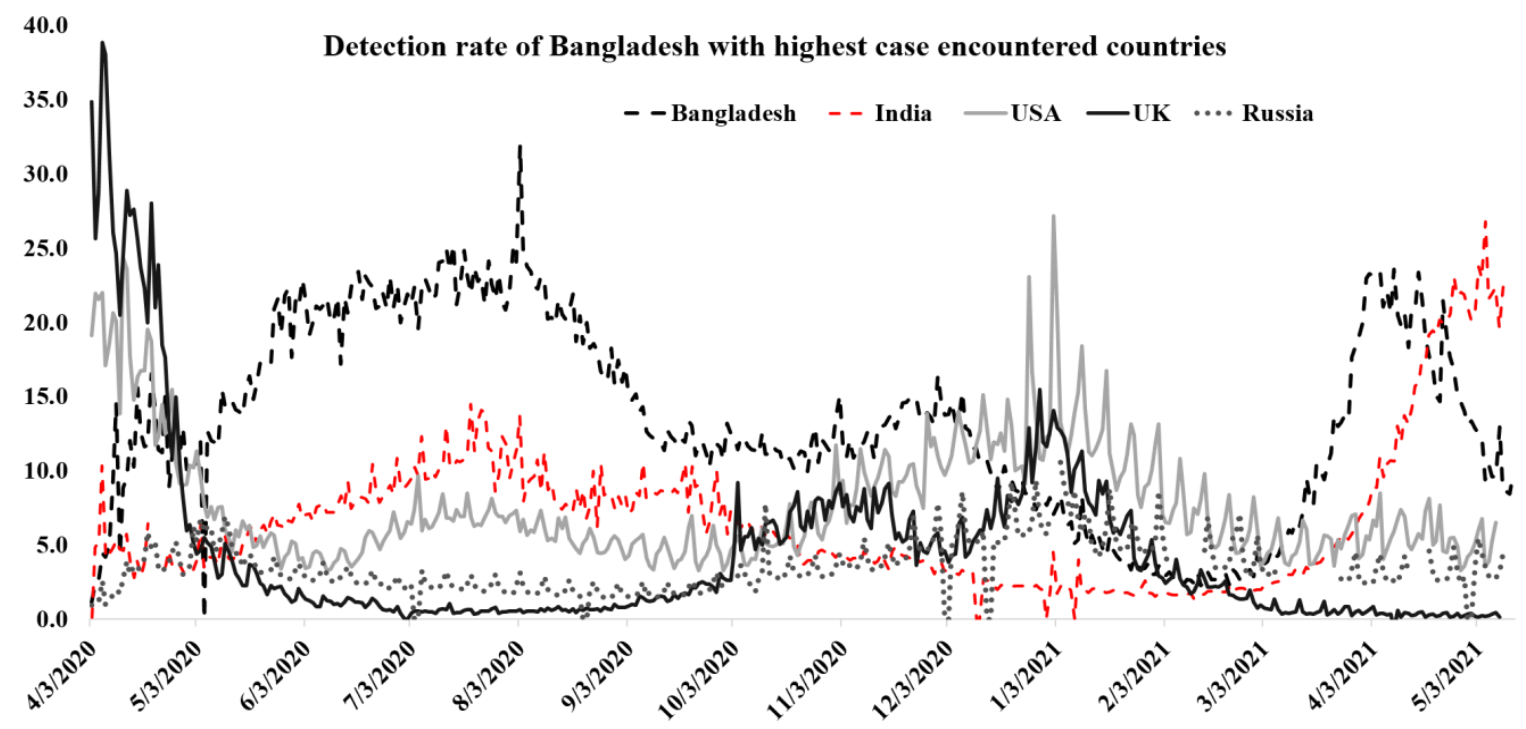

Figure 3 Comparison of SARS-CoV-2 detection rate of Bangladesh with highest case encountered countries. Data source: (https://ourworldindata.org/grapher/positive-rate-daily-smoothed)

4.3 Measures taken to support low-income people and several industries to fight the economic downturn

Considering the plight of low-income citizens across the country, the government announces different stimulus packages and relief facilities. Presuming the upcoming economic loss, the government announced Tk727.50 billion/ $\$ 8$ billion (2.52 percent of GDP) stimulus package to fight the upcoming economic crisis. The GoB has allocated million in cash and 31,000 metric tons of rice for the low-income people all over the country so far (Islam et al., 2020a).

\section{Vaccination Updates of Bangladesh}

Bangladesh started mass vaccination with seven million shots of the Oxford University-AstraZeneca vaccine from February 7, 2021. All the population above 40 years and front line fighters such as health workers, medical technologists, police, public administrator, bankers and their family members were prioritize for the vaccinations. Around 1060 vaccination centers across the country are being used for mass vaccinations. As of May 11, 2021 stopped in many centers. This is a huge obstacle for the country in managing the COVID-19 crisis.

\section{Challenges and limitations faced by the country}

Bangladesh has previous experiences of dealing with regional Dengue and Chikungunya viral outbreaks, however, such experiences were not adequate in handling the COVID-19 pandemic. Being a resource-limited country there were so many challenges from inadequate isolation beds to testing facilities, even creating mass awareness about the pandemic was also challenging. Although government and private organizations implemented several preventive measures at various stages (such as zero cases, scattered cases, case groups, community transmissions, or nationwide infections) according to WHO guidelines, more needs to be done as the second wave has been started.

\subsection{Challenges at the beginning of the pandemic}

At the beginning of the pandemic expatriates from all over the world returned to their native countries (Monjur \& Hassan, 2020). 
But initially, the cover-up of past travel history by returnees proved to be the worst point of the Bangladesh scenario. Among the first three, one case has proven to be in contact with returnees from Italy (Corona.info.bd/press-release, 2020; Monjur \& Hassan, 2020). Failure to understand the urgency allows local, regional, and national communities to be affected by the pandemic. It was also reported that people were confused with certain English terms such as "stay at home," "social distancing," "quarantine," and "lockdown" (Siam et al., 2020).

\subsection{Challenges in healthcare facilities}

Developed countries with highly efficient medical infrastructure such as the United States, United Kingdom, Italy, and Spain were also under a lot of stress and suffered from high death tolls. Similarly, Bangladesh, a low-middle-income South Asian country, is losing its battle against the pandemic, largely because of its inefficient healthcare system. The casualties are escalating and public sufferings are becoming unimaginable (Al-Zaman, 2020). During the early time of the pandemic, a large group of doctors discontinued private practices and many private clinics and hospitals closed their services, moreover, hospitals also refused to admit patients with flu-like symptoms (Al-Zaman, 2020; Rahaman et al., 2020). Gradually, such problems were overcome due to mass awareness. However, there are around 100 thousand registered doctors in Bangladesh and they are facing difficulties in providing quality service to a large group of infected persons. As we mentioned earlier, the number of general beds and ICU beds were also not sufficient considering thousands of reported cases every day. The number of general and ICU beds should be increased to mitigate any future large outbreak like the Indian second wave. Apart from these, one of the major problems is testing centers are located in large cities, most of the remote districts have no testing facilities for COVID-19 (Rahaman et al., 2020). However, GoB is gradually increasing testing facilities all over the country and also appointing many new doctors

\subsection{Health status of the citizens}

Some reports described older age and several co-morbidities were also associated with higher severity and mortality in patients with both COVID-19 (Chevance et al., 2020; Jin et al., 2020; Ningthoujam \& Khomdram, 2020), and the global report also suggests that the elderly are at the highest risk in the fight against the coronavirus (Ningthoujam \& Khomdram, 2020). About 14\% of the population in Bangladesh is about 55 years of age or older (Indexmundi, 2020), and a large number of the population including senior citizens are affected by non-communicable diseases like cancer, cardiovascular disease, diabetes, asthma, bronchitis, chronic obstructive pulmonary disease, etc. (Anwar et al., 2020; Islam et al., 2020b). Sadly, most of the deaths in the elderly with comorbidities are on the rise, the highest CFR rate has been observed in males with average age of more than 51 years in Bangladesh (WHO-Situation-Reports, 2021). Such noncommunicable diseases (NCDs) are emerging as the major causes of morbidity and mortality, accounting for $61 \%$ of deaths before the pandemic also (Biswas et al., 2017). Among the South Asian countries, Bangladesh has the highest prevalence of smokers (Bishwajit et al., 2017). Although there is still no direct evidence that smoking is associated with severe COVID-19 related complications, perhaps there is a correlation (Cai, 2020).

\subsection{Challenges in controlling the spread of corona in slums and} refugee camps

Implementing social distancing and personal hygiene is challenging in heavily populated countries like Bangladesh. To maintain social distance during this pandemic is difficult in some living places such as in slums, where residents have to share toilets, kitchens and even beds (Ahmed et al., 2020; Islam et al., 2021). For example, in the capital Dhaka, there are more than 3000 slums inhabited by over six hundred thousand people and about $75 \%$ of households have to share single room (Islam et al., 2021). Household earning of these people is less than $100 \mathrm{USD} / \mathrm{month}$ and they spend most of their earning (70\%) on food and accommodation (Latif et al., 2016). They are not always able to afford soap and other commodities required for personal hygiene and most of these slums have irregular water supplies also (Haque et al., 2020; Latif et al., 2016). A study done on slum dwellers in Bangladesh revealed that the majority them have limited knowledge of COVID-19 and poor personal hygiene practices (i.e. face mask and hand protection) were commonly observed (Islam et al., 2021).

Bangladesh hosts approximately 1 million Rohingya refugees from Myanmar (Cousins, 2018). The site of the Kutupalong-Balukhali extension holds more than 46,000 inhabitants per square kilometer, which may be one of the most densely populated settlements in the world (Truelove et al., 2020). Majority of the refugee have no basic idea about sanitation and personal hygiene, which makes these refugee camps more vulnerable places for rapid spread of the COVID-19 virus in this pandemic situation (Rahaman et al., 2020). Till now, according to last WHO Rohingya Crisis situation report (08), only 525 refugees were infected and 11 deaths so far due to COVID-19 (https://www.who.int/bangladesh/emergencies/Rohingyacrisis/situ ation-report---rohingya-crisis). However, it will be difficult to suppress the spread of the coronavirus in slums or refugee camps if uncontrolled spread starts, as lockdowns and maintenance of social distancing are far more difficult to implement there (Anwar et al., 2020). But various government and non-government organizations are spreading social awareness to those inhabitants (Sullivan, 2020). Educating the public about the risks of COVID-19 is the real challenge for the government for now and the ways people can protect themselves. 


\subsection{Challenges in the economic sector}

Pandemic did not only challenge the health care settings of the world but also shaken the economic sectors badly. The two largest contributors to Bangladesh's foreign exchange reserves are readymade garments (RMG) industries and remittances from foreign workers. Out of around 63 million employed population of Bangladesh, around 10 million people are casual daily wagers, 4.5 million are casual laborers and 4 million are RMG workers and they were in the most vulnerable state due to the pandemic (Islam et al., 2020a). RMG industries faced huge cancellation of preorders and authorities also announced the closure of all garments to curb the spread of COVID-19. As the lockdown continues, about a million RMG workers lost their jobs and did not receive their salary of the previous months, and companies also got shut down (Shammi et al., 2020). If we consider the overall situation, economically it is not feasible for a low middle-income country to shut down all the factories and industries due to the lockdown. Though the government implemented several stimulus packages and relief funds for the low-income people, it is usual that it cannot be adopted for the long runs. To find a way out of the impending recession, the government had decided to open factories, shopping malls and various industries by ensuring proper social distance and personal hygiene. However, irregularities are being noticed in shopping malls and various factories in adhering to social distances and proper hygiene, due to which the number of new cases is increasing day by day. Sadly, when the country seems to recover from the COVID-19 losses, suddenly many people are at risk of returning below the poverty line again as the second country wise lockdown started in April, 2021. However, GoB decided to keep open all the RMG to cover the economic loss, while other workers are facing dire situations to support their families as several constructions, transport, trade, and food, and accommodation businesses are seriously affected by the lockdown. A report described that around 72 million people are now facing the challenge of livelihood during the pandemic (Islam et al., 2020a). It is also seen that people are not afraid of corona anymore as losing a job is far fearful and negligence of social distancing and personal hygiene increasing the infected.

With the passage of time, the awareness of people about COVID19 has been decreasing, and social media and government persuasions have not been able to raise the issue in any way. Although it is compulsory to wear a mask, the general public is showing reasons for not wearing a mask on various pretexts. Looking at the situation of Vietnam, one can surely tell how everybody should come forward in this situation to control the pandemic. The country first detected the COVID-19 test in January, 2020. Being a LMI country with most visitor from China still manage to count only around 1500 cases which is a lesson to learn for other countries (Quach \& Hoang, 2020). Moreover,
Bhutan, Maldives, and Sri Lanka have also been successfully reducing the spread of the virus (Sarkar et al., 2020).

Lockdown may be one of the best-known measures that could slow down the rate of infection (Lau et al., 2020). A region like Bangladesh where small portions of population are vaccinated so far, it is perhaps only effective measure that could mitigate the situation. It is indeed a difficult task to confined people in their home space and maintains social distance. However, at the beginning of the second wave in April 2021, GoB imposed lockdown and the result seems satisfactory as the infection rate dropped down from $24 \%$ to around $9 \%$ in May first week (DGHSCOVID-19-Dashboard, 2020). The police and armed forces are trying hard to make people understand the importance of social distance still some discrepancies are seen all over the country. However, more thoughtful actions are needed to straighten the infection curve in the future. Bangladesh needs more budget and administrative strategic actions. As mass vaccination is not possible in all over the world for COVID-19, safe hygienic practices are perhaps the best-known measure that could mitigate the situation.

\section{Conclusion and Future Prospects}

Proper management and social awareness could prevent the further spread of this rampant virus. Lessons learned from the previous pandemic indicates that simple measures were able to tackle big pandemics, such as in cholera times, steps as drinking clean water and maintaining proper sanitations were proved to prevent the diseases. Understanding the ongoing situation it is clear that increasing public awareness and maintaining social distance can only stop the further transmission. It is not possible to stop the pandemic in a short time with mass vaccination. Thus the government need more drastic and long term measures to stop the transmission and also needs to increase all medical facilities to deal with the huge number of patients in worsen case scenario. As government can't fight this battle alone, individual efforts from citizens and public health experts are needed to ensure the confinement of the virus to stop the transmission.

Conflict of Interest: The authors declare that they have no conflict of interest.

\section{References}

Ahmed N, Rony RJ, Zaman KT (2020) Social distancing challenges for marginal communities during COVID-19 pandemic in Bangladesh. Journal of Biomedical Analytics 3(2):5-14.

Al-Zaman MS (2020) Healthcare Crisis in Bangladesh during the COVID-19 Pandemic. The American Journal of Tropical Medicine and Hygiene 103(4):1357-1359. 
Anwar S, Nasrullah M, Hosen MJ (2020) COVID-19 and Bangladesh: Challenges and How to Address Them. Frontiers in Public Health https://doi.org/10.3389/fpubh.2020.00154.

Bishwajit G, Tang S, Yaya S, Feng Z (2017) Burden of asthma, dyspnea, and chronic cough in South Asia. International Journal of Chronic Obstructive Pulmonary Disease 12:1093-1099.

Biswas T, Pervin S, Tanim MIA, Niessen L, Islam A (2017) Bangladesh policy on prevention and control of noncommunicable diseases: a policy analysis. BMC Public Health 17(1):582-582.

Bwire GM (2020) Coronavirus: Why Men are More Vulnerable to Covid-19 Than Women? SN comprehensive clinical medicine:1-3.

Cai H (2020) Sex difference and smoking predisposition in patients with COVID-19. Lancet Respiratory Medicine 8(4):e20. DOI:https://doi.org/10.1016/S2213-2600(20)30117-X.

Chevance A, Gourion D, Hoertel N, Llorca PM, Thomas P, Bocher R, et al. (2020) Ensuring mental health care during the SARSCoV-2 epidemic in France: A narrative review. Encephale 46(3):193-201.

Corona.info.bd/press-release (2020) Available at https://corona.gov.bd/press-release. Accessed: May 11, 2021,

Cousins S (2018) Rohingya threatened by infectious diseases. Lancet Infectious Diseases 18(6):609-610.

DGHS-COVID-19-Dashboard (2020) Directorate General of Health Services, Ministry of Health and Family Welfare, Government of The People's Republic of Bangladesh. Retrieved from http://103.247.238.81/webportal/pages/covid19.php. Accessed: May 11, 2021.

Dhaka_Tribune (2020) World's 2nd largest Covid-19 hospital opens in Bangladesh.May 17, 2020. Retrieved from https://www.dhakatribune.com/health/coronavirus/2020/05/17/wor ld-s-2nd-largest-covid-19-hospital-opens-in-bangladesh. Accessed: December 10, 2020.

Emon EKH, Alif AR, Islam MS (2020) Impact of COVID-19 on the Institutional Education System and its Associated Students in Bangladesh. Asian Journal of Education Social Studies:34-46.

Farsalinos K, Poulas K, Kouretas D, Vantarakis A, Leotsinidis M, Kouvelas D, et al. (2021) Improved strategies to counter the COVID-19 pandemic: Lockdowns vs. primary and community healthcare. Toxicol Repots 8: 1-9. DOI: https://doi.org/10.1016/j.toxrep.2020.12.001.
Gbadamosi AQ, Oyedele L, Olawale O, Abioye S (2020) Offsite Construction for Emergencies: A focus on Isolation Space Creation (ISC) measures for the COVID-19 pandemic. Progress in Disaster Science 8:100130-100130. DOI: https://doi.org/10.1016/j.pdisas.2020.100130.

Gómez CE, Perdiguero B, Esteban M (2021) Emerging SARSCoV-2 Variants and Impact in Global Vaccination Programs against SARS-CoV-2/COVID-19. Vaccines 9(3):243.

Griffin S (2020) Covid-19: Failure to control pandemic and inequalities made England worst affected in Europe, says report. BMJ 371:m4842. DOI: http://dx.doi.org/10.1136/bmj.m4842

Haque SS, Yanez-Pagans M, Arias-Granada Y, Joseph G (2020) Water and sanitation in Dhaka slums: access, quality, and informality in service provision. Water International 45(7-8):791811.

United News of Bangladesh (2020) http://unb.com.bd/category/Bangladesh/virtual-trial-proceedingsbegin-in-dhaka-courts/51449.

HDX (2019) Novel Coronavirus (COVID-19) Cases Data Available at https://data.humdata.org/dataset/novel-coronavirus2019-ncov-cases. Accessed: May 11, 2021

Our World in data (2021) The share of COVID-19 tests that are positive, May 16, 2021. Available at https://ourworldindata.org/grapher/positive-rate-daily-smoothed. Accessed: May 11, 2021

Indexmundi (2020) Bangladesh Demographics Profile 2019. Retrieved from https://www.indexmundi.com/bangladesh/demographics_profile.ht ml. Accessed: May 11, 2021.

Islam MT, Talukder AK, Siddiqui MN, Islam T (2020a) Tackling the COVID-19 pandemic: The Bangladesh perspective. Journal of Public Health Research 9(4):1794.

Islam S, Emran GI, Rahman E, Banik R, Sikder T, Smith L, et al. (2021) Knowledge, attitudes and practices associated with the COVID-19 among slum dwellers resided in Dhaka City: a Bangladeshi interview-based survey. Journal of public health (Oxford, England) 43(1):13-25.

Islam S, Islam R, Mannan F, Rahman S, Islam T (2020b) COVID19 pandemic: An analysis of the healthcare, social and economic challenges in Bangladesh. Progress in Disaster Science 8:100135.

Jin JM, Bai P, He W, Wu F, Liu XF, Han DM, et al. (2020) Gender Differences in Patients With COVID-19: Focus on Severity and Mortality. Frontiers in public health 8:152-152. 
Latif MB, Irin A, Ferdaus J (2016) Socio-economic and health status of slum dwellers of the Kalyanpur slum in Dhaka city. Bangladesh Journal of Scientific Research 29(1):73-83.

Lau H, Khosrawipour V, Kocbach P, Mikolajczyk A, Schubert J, Bania J, et al. (2020) The positive impact of lockdown in Wuhan on containing the COVID-19 outbreak in China. Journal of Trave Medicine 27(3):taaa037. doi: 10.1093/jtm/taaa037.

Mahajan NN, Pednekar R, Patil SR, Subramanyam AA, Rathi S, Malik S, et al. (2020) Preparedness, administrative challenges for establishing obstetric services, and experience of delivering over 400 women at a tertiary care COVID-19 hospital in India International Journal of Gynocology \& Obstetrics 151(2):188-196. DOI: https://doi.org/10.1002/ijgo.13338.

Moin AT, Sakib MN, Araf Y, Sarkar B, Ullah MA (2020) Combating COVID-19 pandemic in Bangladesh: a memorandum from developing country. European Journal of Medical and $\begin{array}{llll}\text { Educational Technologies } 13 & \text { (4):em2017. DOI }\end{array}$ https://doi.org/10.30935/ejmets/8571.

Monjur MR, Hassan MZ (2020) Early phases of COVID-19 management in a low-income country: Bangladesh. Infection Control and Hospital Epidemiology 41(9):1116-1117.

Ningthoujam R, Khomdram D (2020) WHO statement - "Older people are at highest risk from COVID-19": Should the hypothesis be corroborated or rejected? Medical Hypotheses 144:109896.

NPRP (2020) National Preparedness and Response Plan for COVID-19, Bangladesh. Retrieved from Bangladesh:Available at https://app.adpc.net/publications/national-preparedness-andresponse-plan-covid-19-bangladesh retrive on 11th May 2021.

MoHFW (2020) Report of Ministry of Health and Family Welfare http://www.mohfw.gov.bd/index.php?option=com_docman\&task= doc_download\&gid=23359\&lang=en Retrive from 11 May 2021.

Plante JA, Mitchell BM, Plante KS, Debbink K, Weaver SC, Menachery VD (2021) The variant gambit: COVID-19's next move. Cell Host \& Microbe 29(4):508-515.

Quach HL, Hoang NA (2020) COVID-19 in Vietnam: A lesson of pre-preparation. Journal of Clinical Virology 127:104379.

Quadri SA (2020) COVID-19 and religious congregations: Implications for spread of novel pathogens. International journal of infectious diseases : IJID : official publication of the International Society for Infectious Diseases 96:219-221.

Rahaman KR, Mahmud MS, Mallick B (2020) Challenges of Testing COVID-19 Cases in Bangladesh. International Journal of
Environmental Research and Public Health 17(18): 6439. doi: 10.3390/ijerph17186439.

Sakib SN (2020) COVID-19: Bangladesh halts prayers at mosques. Anadolu Agency.April 6, 2020) Retrieved from https://www.aa.com.tr/en/asia-pacific/covid-19-bangladesh-haltsprayers-at-mosques/1794191 . Accessed July 12, 2020.

Samad N, Sodunke TE, Banna HA, Sapkota A, Fatema AN, Iskandar K, et al. (2020) Convalescent Plasma Therapy for Management of COVID-19: Perspectives and Deployment in the Current Global Pandemic. Risk Management and Healthcare Policy 13:2707-2728.

Sarkar A, Liu G, Jin Y, Xie Z, Zheng Z-J (2020) Public health preparedness and responses to the coronavirus disease 2019 (COVID-19) pandemic in South Asia: a situation and policy analysis. Global Health Journal 4(4):121-132.

Shammi M, Bodrud-Doza M, Islam ARMT, Rahman MM (2020) Strategic assessment of COVID-19 pandemic in Bangladesh: comparative lockdown scenario analysis, public perception, and management for sustainability. Environment, Development and Sustainability 23: 6148-6191. DOI: https://doi.org/10.1007/s10668-020-00867-y.

Siam MHB, Hasan MM, Raheem ME, Khan HR, Siddiqee MH, Hossain MS (2020) Insights into the first wave of the COVID-19 pandemic in Bangladesh: Lessons learned from a high-risk country. medRxiv.

Sullivan DP (2020) COVID-19 in Rohingya refugee camps a 'nightmare scenario'. Reliefweb. Retrieved from https://reliefweb.int/report/bangladesh/COVID-19-rohingyarefugee-camps-nightmare-scenario Access on 14 May 2020.

Truelove S, Abrahim O, Altare C, Lauer SA, Grantz KH, Azman AS, et al. (2020) The potential impact of COVID-19 in refugee camps in Bangladesh and beyond: A modeling study. PLoS Medicine 17(6):e1003144-e1003144.

Vahidy FS, Pan AP, Ahnstedt H, Munshi Y, Choi HA, Tiruneh Y, et al. (2021) Sex differences in susceptibility, severity, and outcomes of coronavirus disease 2019: Cross-sectional analysis from a diverse US metropolitan area. PloS One 16(1):e0245556.

Wang C, Horby PW, Hayden FG, Gao GF (2020) A novel coronavirus outbreak of global health concern. Lancet 395(10223):470-473

WHO-Situation-Reports (2021) WHO-Situation-Reports Retrived from https://www.who.int/bangladesh/emergencies/coronavirusdisease-(covid-19)-update/coronavirus-disease-(covid-2019)bangladesh-situation-reports. Accessed: May 11, 2021. 